\title{
Manganese-Catalyzed Ammonia Oxidation into Dinitrogen
}

\author{
Hiroki Toda, ${ }^{\dagger}$ Kazunari Nakajima, ${ }^{\ddagger}$ Ken Sakata, ${ }^{*}$ Y Yoshiaki Nishibayashi* ${ }^{\dagger}$ \\ ${ }^{\dagger}$ Department of Systems Innovation, School of Engineering, The University of Tokyo, Hongo, Bunkyo-ku, Tokyo 113-8656, \\ Japan \\ ${ }^{\ddagger}$ Frontier Research Center for Energy and Resources, School of Engineering, The University of Tokyo, Hongo, Bunkyo-ku, \\ Tokyo 113-8656, Japan \\ ${ }^{\S}$ Faculty of Pharmaceutical Sciences, Toho University, Miyama, Funabashi, Chiba 274-8510 Japan
}

\author{
Supporting Information Placeholder
}

Ammonia is a desirable candidate as an energy carrier toward a sustainable society because of its advantages such as the easiness of handling, high energy density, and zero carbon content. ${ }^{1}$ For extracting energy directly from ammonia, catalytic ammonia oxidation, in which two ammonia molecules are oxidatively converted into dinitrogen, six electrons, and six protons, has recently emerged as an attractive process (eq. 1). In addition, this transformation has some advantages including environmental solutions for denitrification $^{2}$ and inverse molecular models of nitrogen fixation such as the Haber-Bosch process. ${ }^{3}$

$2 \mathrm{NH}_{3} \longrightarrow \mathrm{N}_{2}+6 \mathrm{e}^{-}+6 \mathrm{H}^{+}$

Conversion of ammonia into dinitrogen has been developed mainly in the field of heterogeneous catalysis. To date, electrochemical oxidations and thermal decomposition reactions of ammonia into dinitrogen and dihydrogen have been intensively studied. ${ }^{4}$ Conversely, in the field of coordination chemistry, only a few successful examples of catalytic oxidation of ammonia into dinitrogen have been reported so far. In 2019, Hamman, Smith, and co-workers reported a catalytic ammonia oxidation reaction using a ruthenium ammonia complex bearing polypyridyl ligands under electrochemical oxidation conditions. ${ }^{5}$ In the same year, Mock and co-worker demonstrated catalytic ammonia oxidation reactions via hydrogen atom transfer using a (pentamethylcyclopentadienyl)ruthenium complex, where a phenoxyl radical derivative worked as a hydrogen atom acceptor. ${ }^{6}$ At the same time, independently, our group realized a catalytic ammonia oxidation using an oxidant and a base in the presence of a ruthenium complex bearing a bipyridine dicarboxylate ligand. ${ }^{7}$ In these reaction systems, the use of ruthenium catalysts was essential to promote the ammonia oxidation reaction effectively. ${ }^{8}$ Afterward, as the first example of an ammonia oxidation reaction using a catalyst based on iron as abundant first-row metal, Peters and co-workers reported an electrocatalytic conversion of ammonia into dinitrogen and dihydrogen. ${ }^{9,10}$ However, to the best of our knowledge, other base metal complexes have not been used yet for the catalytic oxidation of ammonia.

Motivated by the aforementioned, we have focused on first-row metal complexes bearing an $N, N$ '-ethylenebis(salicyldeneamine) (salen) ligand because the catalytic activity of these complexes toward various oxidation reactions in organic synthesis has been demonstrated. ${ }^{11}$ In particular, manganese salen complexes serve as effective catalysts for several oxidation reactions such as epoxidation of olefins, benzylic oxidation, and sulfide oxidation. ${ }^{12}$ With regard to stoichiometric oxidations of ammonia, the formation of manganese nitride complexes from the reaction of ammonia with $\mathrm{NaOCl}$ as a strong oxidant in the presence of manganese salen complexes was reported. ${ }^{13}$ Other research groups demonstrated nitride-nitride coupling reactions between manganese nitride complexes bearing salen ligands in the presence of single-electron oxidants to generate dinitrogen. ${ }^{14}$ On the basis of these research backgrounds, we envisaged that manganese complexes bearing salen ligands could work as catalysts toward ammonia oxidation reactions. Herein, we report the first successful manganese-catalyzed oxidation of ammonia under chemical and electrochemical oxidation conditions. 
First, as a manganese catalyst, we selected commercially available manganese chloride complex (1) bearing $(1 S, 2 S)$ $N, N^{\prime}$-bis(3,5-di-tert-butylsalicylidene)-1,2-

cyclohexanediamine as ligand. ${ }^{12 \mathrm{a}}$ A mixture of ammonium triflate $\left(\mathrm{NH}_{4} \mathrm{OTf}, 3.0 \mathrm{mmol}\right)$ as an ammonia source, tris $(4-$ bromophenyl)aminium hexachloroantimonate $(\mathbf{2} ; 0.90$ $\mathrm{mmol})$ as an oxidant, 2,4,6-collidine $(3.0 \mathrm{mmol})$ as a base, and a catalytic amount of $1(0.010 \mathrm{mmol})$ was reacted in $\mathrm{MeCN}$ at $-40{ }^{\circ} \mathrm{C}$ for $2 \mathrm{~h}$ and then at room temperature for a further $4 \mathrm{~h}$ to give 4.3 equiv of dinitrogen per manganese atom of the catalyst in $29 \%$ yield based on the oxidant (Table 1, run 1). The use of 2,6-lutidine and pyridine as bases instead of 2,4,6-collidine under the same reaction conditions afforded 1.0 equiv and 0.1 equiv of dinitrogen, respectively (Table 1, runs 2 and 3 ). The reaction of aqueous ammonia as an ammonia source instead of $\mathrm{NH}_{4} \mathrm{OTf}$ gave 1.7 equiv of dinitrogen together with a small amount of hydrazine (Table 1, run 4). It is noteworthy that hydrazine was formed directly from ammonia, albeit in a small amount.

Next, we investigated reactions in the presence of manganese complexes bearing other salen ligands. The use of a manganese complex containing a less sterically hinder salen ligand (3) gave a lower stoichiometric amount of dinitrogen (Table 1, run 5). Conversely, a manganese complex bearing a bulky salen ligand (4) afforded no reaction (Table 1, run 6). ${ }^{12 \mathrm{~b}}$ These results indicate that complex $\mathbf{1}$ provides the best catalytic activity. Finally, we carried out the reaction with larger substrate-to-catalyst ratios, where up to 17.1 equivalents of dinitrogen were observed (Table 1 , runs 7 and 8). Separately, we confirmed that the generation of dinitrogen required the presence of manganese complex 1, oxidant 2, base, and $\mathrm{NH}_{4} \mathrm{OTf}$ (Supporting Information, Table S1). Additionally, reactions using ${ }^{15} \mathrm{~N}$-labeled ammonium salt demonstrated that the generated dinitrogen was derived from ammonia (Supporting Information, Table S2). Table 1. Catalytic Ammonia Oxidation with Manganese Complexes

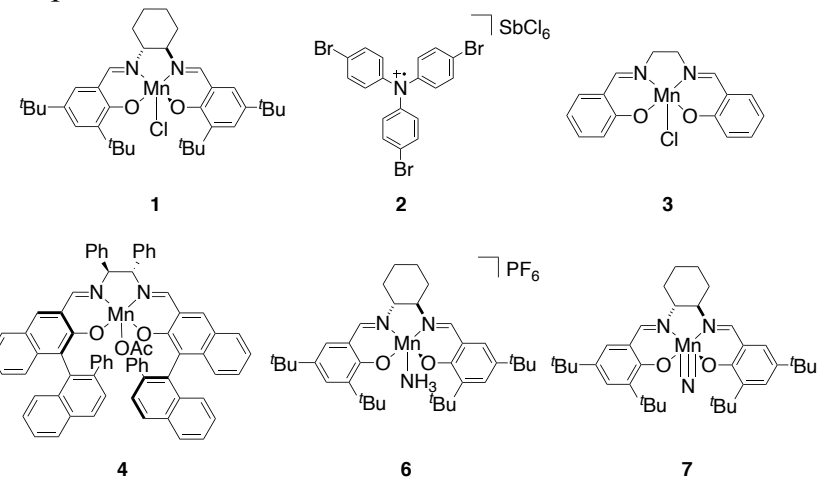

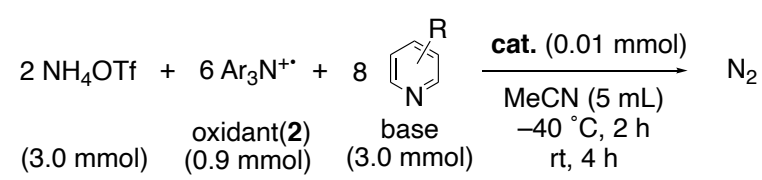

\begin{tabular}{ccccc} 
run & cat. & base & $\mathrm{N}_{2}$ (equiv) & $\mathrm{N}_{2}(\%)^{a}$ \\
\hline 1 & $\mathbf{1}$ & $2,4,6$-collidine & $4.3 \pm 0.5$ & $29 \pm 3$ \\
2 & $\mathbf{1}$ & 2,6-lutidine & 1.0 & 7 \\
3 & $\mathbf{1}$ & pyridine & 0.1 & 1 \\
$4^{b}$ & $\mathbf{1}$ & $2,4,6$-collidine & $1.7^{c}$ & 11 \\
5 & $\mathbf{3}$ & $2,4,6$-collidine & 0.7 & 5 \\
6 & $\mathbf{4}$ & $2,4,6$-collidine & 0 & 0 \\
$7^{d}$ & $\mathbf{1}$ & $2,4,6$-collidine & $8.7 \pm 0.5$ & $29 \pm 2$ \\
$8^{d, e}$ & $\mathbf{1}$ & $2,4,6$-collidine & 17.1 & 14 \\
9 & $\mathbf{6}$ & $2,4,6$-collidine & 3.0 & 20 \\
10 & $\mathbf{7}$ & $2,4,6$-collidine & 2.7 & 16 \\
\hline
\end{tabular}

Reactions of ammonium triflate $(3.0 \mathrm{mmol}), 2(0.9 \mathrm{mmol})$, and base $(3.0$ $\mathrm{mmol})$ were carried out in the presence of manganese catalyst $(0.01 \mathrm{mmol})$ under an $\mathrm{Ar}$ atmosphere at $-40{ }^{\circ} \mathrm{C}$ for $2 \mathrm{~h}$ and then at room temperature for 4 h. ${ }^{a}$ Based on oxidant. ${ }^{b} \mathrm{NH}_{3}$ aq $(3.0 \mathrm{mmol})$ was used instead of $\mathrm{NH}_{4} \mathrm{OTf}$. ${ }^{c} \mathrm{NH}_{2} \mathrm{NH}_{2}$ (0.15 equiv) was observed. ${ }^{d} \mathrm{NH}_{4} \mathrm{OTf}(6.0 \mathrm{mmol}), 2(1.8 \mathrm{mmol})$, and base $(6.0 \mathrm{mmol})$ were used. ${ }^{e} \mathbf{1}(0.0025 \mathrm{mmol})$ was used.

To obtain a mechanistic insight into this process, we attempted the isolation of reactive intermediates from stoichiometric reactions (Scheme 1). Treatment of a cationic complex of 1 (5) with an excess amount (80 equiv) of ammonia at room temperature for $10 \mathrm{~min}$ in $\mathrm{MeOH}$ gave the corresponding manganese ammonia complex (6) in $36 \%$ yield. Recrystallization of $\mathbf{6}$ from $\mathrm{MeOH}$ afforded a manganese ammonia complex with additional $\mathrm{MeOH}$ coordinated to the manganese atom $(\mathbf{6} \cdot \mathbf{M e O H})$ as brown crystals. The molecular structure of $\mathbf{6} \cdot \mathbf{M e O H}$ was unambiguously determined by X-ray analysis, an ORTEP drawing of which is shown in Scheme 1. From the structure of $\mathbf{6} \cdot \mathbf{M e O H}$, it was revealed that both ammonia and methanol coordinate to the metal center at the axial position. We confirmed that complex $\mathbf{6}$ has a similar catalytic activity to that of $\mathbf{1}$ toward ammonia oxidation (Table 1, run 9).

Next, to explore the possibility of the formation of a nitride complex under the current reaction conditions, we examined the stoichiometric reaction of manganese ammonia complex 6 with 6 equiv of 2 as an oxidant and 30 equiv of 2,4,6-collidine as a base. However, no formation of nitride complex (7) was observed at all by ${ }^{1} \mathrm{H}$ NMR, IR spectra, and ESI-MS. These results indicate that nitride species might not be generated in the current reaction system. 

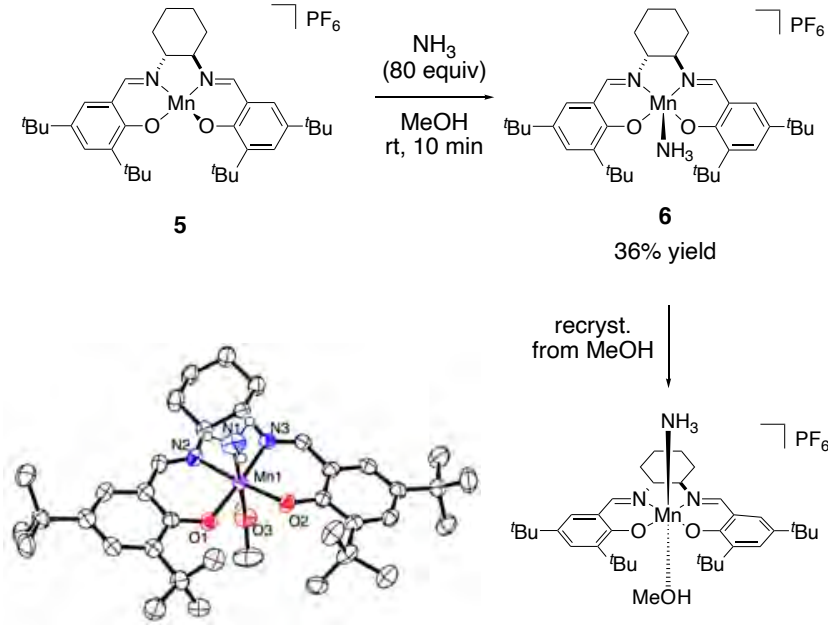

Scheme 1. Synthesis of reaction intermediate.

$6 \cdot \mathrm{MeOH}$

To obtain information on the reaction pathway, we conducted some stoichiometric reactions of manganese ammonia complex $\mathbf{6}$. Treatment of $\mathbf{6}$ with 6 equiv of $\mathbf{2}$ as an oxidant and 300 equiv of 2,4,6-collidine as a base in $\mathrm{MeCN}$ resulted in no formation of dinitrogen (Scheme 2a, top). By contrast, when conducting a similar reaction in the presence of excess amount (300 equiv) of $\mathrm{NH}_{4} \mathrm{OTf}$, the formation of dinitrogen was observed in $25 \%$ yield based on the manganese atom of $\mathbf{6}$ (Scheme 2a, bottom). These stoichiometric results indicate that nitrogen gas may be formed from reactions of manganese nitrogenous complexes derived from manganese ammonia complex $\mathbf{6}$ in the presence of an external ammonia source. To get direct evidence of the reaction pathway, we performed some ${ }^{15} \mathrm{~N}$-labeling experiments. When the reaction of 6 with 6 equiv of oxidant and an excess amount of ${ }^{15} \mathrm{NH}_{4} \mathrm{OTf}$ and base was carried out in $\mathrm{MeCN}$ at $-40{ }^{\circ} \mathrm{C}$ for $1 \mathrm{~h},{ }^{15} \mathrm{~N}^{14} \mathrm{~N}$ was observed as the dominant product together with a negligible amount of ${ }^{15} \mathrm{~N}_{2}$ (Scheme $2 b$ ). However, the reaction of the manganese ${ }^{15} \mathrm{~N}$ labeled-ammonia complex $6-{ }^{15} \mathbf{N}$ with an excess amount of ${ }^{14} \mathrm{NH}_{4} \mathrm{OTf}$ under the same reaction conditions resulted in the dominant formation of ${ }^{15} \mathrm{~N}^{14} \mathrm{~N}$ (Scheme 2c). These labeling experiments are consistent with the formation of a nitrogen-nitrogen bond between the manganese nitrogenous complexes and ammonia.

Next, we examined the kinetic isotope effect (KIE) of the catalytic reaction using deuterated ammonium salt $\left(\mathrm{ND}_{4} \mathrm{OTf}\right)$ as an ammonia source in the presence of $\mathbf{1}$. The reaction rate was estimated from the increase in internal pressure measured by a differential pressure gauge. The ratio of the rate constants $\left(k_{H} / k_{D}\right)$ was estimated to be 4.0 , which suggests that scission of a nitrogen-hydrogen bond of ammonia is involved in the rate-determining step (See Supporting Information).

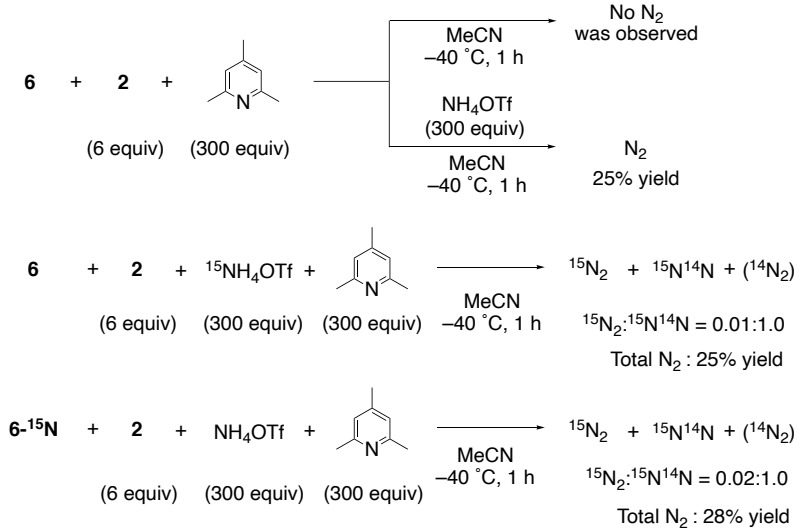

Scheme 2. Mechanistic study.

Subsequently, we investigated the ammonia oxidation reaction under electrochemical oxidation conditions using cyclic voltammetric equipment (Figure 1). The cyclic voltammetry of 1 in the presence of $\mathrm{NH}_{4} \mathrm{OTf}$ and 2,4,6collidine showed an irreversible oxidation wave at $+0.37 \mathrm{~V}$ vs. ferrocene $(\mathrm{Fc})$ probably attributable to the manganese ammonia complex, followed by the catalytic current (Figure 1, (a)). This catalytic current was not observed in the absence of 1 (Figure 1, (b)). The overpotential of ammonia oxidation was estimated to be around $+1.03 \mathrm{~V}$ vs. Fc compared with the theoretical value $\left(-0.53 \mathrm{~V}\right.$ vs. Fc). ${ }^{15}$ From the observed catalytic current, the apparent kinetic constant was estimated to be $k=3.1 \mathrm{~s}^{-1}$. When using $\mathrm{ND}_{4} \mathrm{OTf}$ instead of $\mathrm{NH}_{4} \mathrm{OTf}$, the KIE was estimated to be $k_{\mathrm{H}} / k_{\mathrm{D}}=4.0$, which is similar to that of the catalytic reaction using $\mathbf{2}$ as an oxidant (See Supporting Information).

Interestingly, we found that the first irreversible oxidative wave derived from the ammonia complex shifted to the negative direction on increasing the amount of 2,4,6collidine (Figure 1, onset). This result indicates that a proton-coupled electron transfer (PCET) to the ammonia complex might occur in the first oxidation step because these $\mathrm{pH}$-dependent shifts of the peak potential are generally observed in reactions involving a PCET process. ${ }^{9,16}$

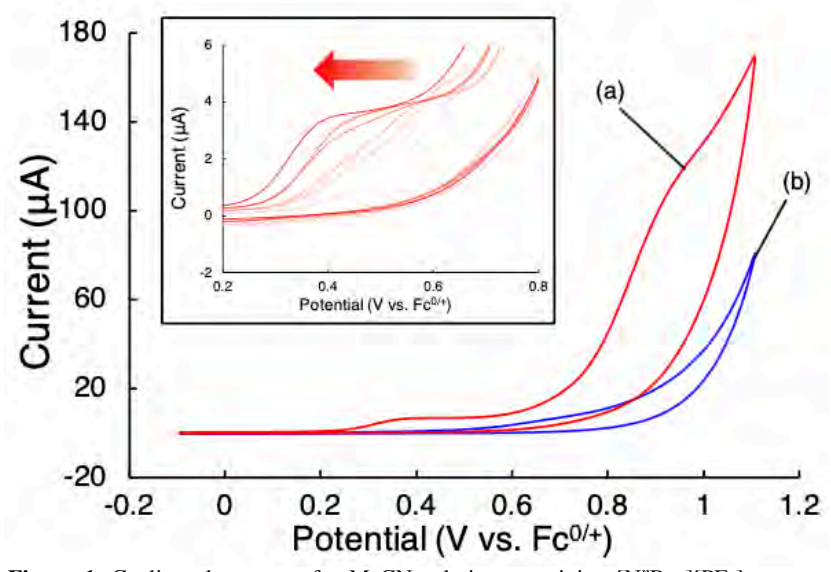

Figure 1. Cyclic voltammetry for $\mathrm{MeCN}$ solution containing $\left[\mathrm{N}^{n} \mathrm{Bu}_{4}\right]\left[\mathrm{PF}_{6}\right]$ at room temperature with a glassy carbon disk working electrode: (a) $\mathbf{1}(1.0 \mathrm{mM}), \mathrm{NH}_{4} \mathrm{OTf}(0.6$ $\mathrm{M})$, and 2,4,6-collidine $(0.6 \mathrm{M})$ with a scan rate $1.0 \mathrm{mVs}^{-1}$; (b) $\mathrm{NH}_{4} \mathrm{OTf}(0.6 \mathrm{M})$ and 2,4,6-collidine $(0.6 \mathrm{M})$ in the absence of catalyst with a scan rate $1.0 \mathrm{mV} \mathrm{s}^{-1}$. Onset: 5 $(1.0 \mathrm{mM})$ and $\mathrm{NH}_{4} \mathrm{OTf}(0.6 \mathrm{M})$ with varying amount of 2,4,6-collidine $(0.038-1.88 \mathrm{M})$. 
On the basis of these experimental results, we propose the reaction pathway shown in Scheme 3. First, manganese ammonia complex $\mathbf{A}$ is formed by ligand exchange of chloride with ammonia. Then, oxidation and deprotonation proceed to afford the corresponding manganese imide complex $([\mathrm{Mn}]=\mathrm{NH}, \mathbf{B})$. Subsequently, the formation of a nitrogennitrogen bond occurs after the nucleophilic attack of ammonia on B. Oxidation and deprotonation then proceed sequentially to afford the corresponding manganese dinitrogen complex $(\mathbf{C})$. Finally, dinitrogen is released by ligand exchange with ammonia together with the regeneration of $\mathbf{A}$. We consider that PCET might proceed in the first oxidation step because of the large KIE observed in the catalytic reactions. ${ }^{17}$ Hydrazine can be formed from the manganese complexes as a reactive intermediate after the nucleophilic attack of ammonia on B. This would explain the small amount of hydrazine observed in the catalytic reaction using aqueous ammonia as an ammonia source (Table 1, run 4). As shown in Table 1, we found that manganese nitride complex 7 worked as a catalyst toward the ammonia oxidation reaction (Table 1 , run 10). In this reaction, the nitride-nitride coupling reaction between the manganese nitride complexes 7 would afford the corresponding ammonia complex $\mathbf{6}$ after the ligand exchange of the dinitrogen-bridged dimanganese complex with ammonia. ${ }^{14 a}$ Then, the ammonia complex would act as a catalyst. Thus, we consider that manganese nitride complex 7 is not a key reactive intermediate of the reaction system.

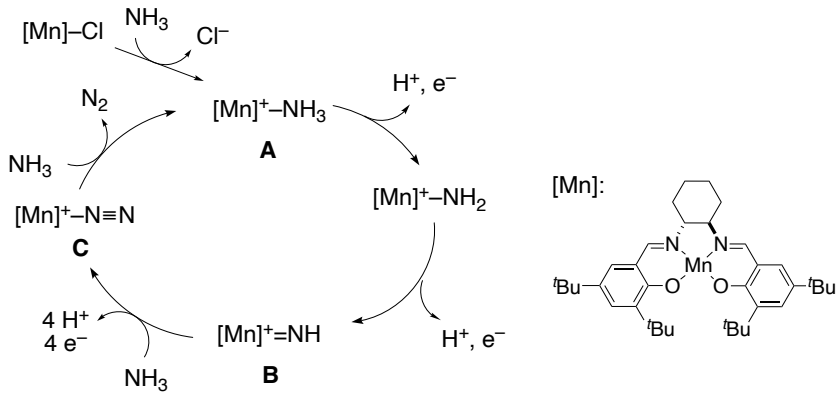

Scheme 3. Plausible reaction mechanism.

The proposed reaction mechanism was supported by DFT calculations at the B3LYP-D3 level (Figure 2). The reaction pathway examined for the model reaction system is shown in Figure 2, onset. In the cationic manganese complex ${ }^{n} \mathbf{I}(n$ $=1,3,5$, and 7 for singlet, triplet, quintet, and septet states, respectively), the quintet-state complex ${ }^{\mathbf{5}} \mathbf{I}$ has the lowest Gibbs free energy. This complex easily coordinates to $\mathrm{NH}_{3}$ via transition state ${ }^{\mathbf{5}} \mathbf{T S}_{\text {I-II }}$ to afford the cationic manganese ammonia complex ${ }^{\mathbf{5}}$ II. Successive oxidation/deprotonation processes give rise to the cationic manganese amide complex ${ }^{4} \mathbf{I V}$ and manganese imide complex ${ }^{3} \mathbf{V I}$. These processes are endothermic, indicating that PCET plays an important role. The attack of the second ammonia molecule to complex ${ }^{3}$ VI leads to complex ${ }^{3}$ VII, which is transferred to the energetically stable quintet-state complex ${ }^{\mathbf{5}}$ VII. While proton migration mediated by 2,4,6-collidine gives manganese hydrazine complex ${ }^{\mathbf{5}} \mathbf{I X}$, oxidation followed by deprotonation affords complex ${ }^{4}$ XI. Subsequent oxidations and deprotonations, which include high exothermic processes, lead to manganese dinitrogen complex ${ }^{5}$ XVII. Thus, the DFT calculations confirm that the transformation from ${ }^{\mathbf{5}} \mathbf{I I}$ to ${ }^{3} \mathbf{V I}$ is the rate-determining step.

In summary, we have achieved the catalytic ammonia oxidation using an oxidant and a base in the presence of a manganese salen complex under chemical and electrochemical oxidation conditions. Complex 1 has the highest catalytic activity for ammonia oxidation; up to 17.1 equivalents of dinitrogen based on the manganese atom of 1 are generated. This is the first successful example of a manganese-catalyzed ammonia oxidation into dinitrogen under ambient reaction conditions. Moreover, the reaction mechanism was examined in detail from experimental and theoretical viewpoints, revealing that a PCET process was involved in the first oxidation step. We believe that this report provides profound insights for the development of a more effective ammonia oxidation process.

\section{ASSOCIATED CONTENT}

Supporting Information

The Supporting Information is available free of charge on the ACS Publications website.

\section{AUTHOR INFORMATION}

\section{Corresponding Author}

E-mail: ken.sakata@phar.toho-u.ac.jp

E-mail: ynishiba@sys.u-tokyo.ac.jp

\section{ORCID}

Hiroki Toda: 0000-0002-6920-0735

Kazunari Nakajima: 0000-0001-9892-5877

Ken Sakata: 0000-0002-6920-0735

Yoshiaki Nishibayashi: 0000-0001-9739-9588

\section{Notes}

The authors declare no competing financial interest.

\section{ACKNOWLEDGMENT}

The present project is supported by CREST, JST (JPMJCR1541). We acknowledge Grants-in-Aid for Scientific Research (JP17H01201, JP18K19093, JP20H00382 (Y.N), and 20K05532(K.S.)) from JSPS and MEXT. H. T. is a recipient of Leadership Development Program for Ph.D in the School of Engineering, the University of Tokyo and the JSPS Predoctoral Fellowships for Young Scientists. 


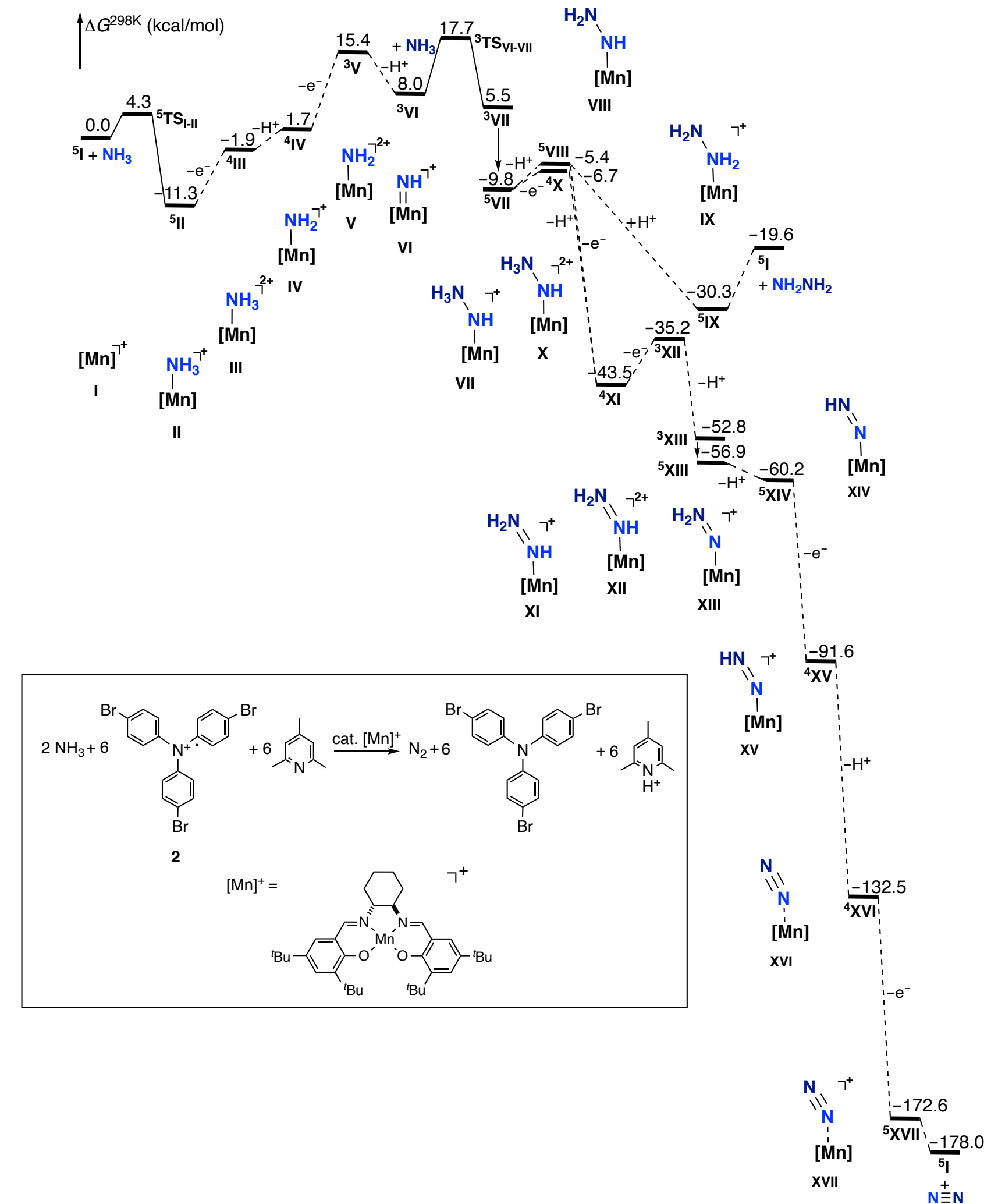

Figure 2. Gibbs free energy diagram. onset: model reaction system for DFT calculations.

\section{REFERENCES}

(1) (a) Service, R. F. Ammonia-A Renewable Fuel Made from Sun, Air, and Water-Could Power the Globe without Carbon. Science 2018, aau7489. DOI: 10.1126/science.aau7489. (b) Guo, J.; Chen, P. Catalyst: $\mathrm{NH}_{3}$ Energy Carrier. Chem 2017, 3, 709-714. (c)Y. Liu; T. J.
Meyer Homogeneous Catalysis for the Nitrogen Fuel Cycle. Proc. Natl. Acad. Sci. U. S. A., 2019, 116, 2794-2795.

(2) Du, R.; Peng, Y.; Cao, S.; Wang, S.; Wu, C. Advanced Nitrogen Removal from Wastewater by Combining Anammox with Partial Denitrification. Bioresour. Technol. 2015, 179, 497-504.

(3) Ertl, G. Reactions at Surfaces: from Atoms to Complexity (Nobel lecture). Angew. Chem. Int. Ed. 2008, 47, 3524-3535.

(4) (a) Adli, N. M.; Zhang, H.; Mukherjee, S.; Wu, G. ReviewAmmonia Oxidation Electrocatalysis for Hydrogen Generation and Fuel Cells. J. Electrochem. Soc. 2018, 165, J3130-J3147. (b) 
Mukherjee, S. et al. Low-temperature Ammonia Decomposition Catalysts for Hydrogen Generation. Appl. Catal. B Environ. 2018, 226, 162-181. (c) Zhong, C.; Hu, W. B.; Cheng, Y. F. Recent Advances in Electrocatalysts for Electro-oxidation of Ammonia. J. Mater. Chem. A 2013, 1, 3216-3238. (d) David, W. I. F.; Makepeace, J. W.; Callear, S. K.; Hunter, H. M. A.; Taylor, J. D.; Wood, T. J.; Jones, M. O. Hydrogen Production from Ammonia Using Sodium Amide. J. Am. Chem. Soc. 2014, 136, 13082-13085. (e) Nagaoka, K.; Eboshi, T.; Takeishi, Y.; Tasaki, R.; Honda, K.; Imamura, K.; Sato, K. Carbonfree $\mathrm{H}_{2}$ Production from Ammonia Triggered at Room Temperature with an Acidic $\mathrm{RuO}_{2} / \gamma-\mathrm{Al}_{2} \mathrm{O}_{3}$ Catalyst. Sci. Adv. 2017, 3, e1602747.

(5) Habibzadeh, F.; Miller, S. L.; Hamann, T. W.; Smith, M. R. Homogeneous Electrocatalytic Oxidation of Ammonia to N2 Under Mild Conditions. Proc. Natl. Acad. Sci. U. S. A. 2019, 116, 2849-2853.

(6) Bhattacharya, P.; Heiden, Z. M.; Chambers, G. M.; Johnson, S. I.; Bullock, R. M.; Mock, M. T. Catalytic Ammonia Oxidation to Dinitrogen by Hydrogen Atom Abstraction. Angew. Chem., Int. Ed. 2019, 58, 11618-11624.

(7) Nakajima, K.; Toda, H.; Sakata, K.; Nishibayashi, Y. Ruthenium-Catalysed Oxidative Conversion of Ammonia into Dinitrogen. Nat. Chem. 2019, 11, 702-709.

(8) Most recently, Bullock and co-worker reported rutheniumcatalyzed ammonia oxidation. Dunn, P. L.; Johnson, S. I.; Kaminsky, W.; Bullock, R. M. Diversion of Catalytic C-N Bond Formation to Catalytic Oxidation of $\mathrm{NH}_{3}$ Through Modification of the Hydrogen Atom Abstractor. J. Am. Chem. Soc. 2020, 142, 3361-3365.

(9) Zott, M. D.; Garrido-Barros, P.; Peters, J. C. Electrocatalytic Ammonia Oxidation Mediated by a Polypyridyl Iron Catalyst. ACS Catal. 2019, 9, 10101-10108.

(10) Also see a relevant study recently posted to ChemRxiv: Raghibi Boroujeni, M.; Greene, C.; Bertke, J. A.; Warren, T. H. Chemical and Electrocatalytic Ammonia Oxidation by Ferrocene. ChemRxiv 2019, DOI: 10.26434/chemrxiv.9729635.v1.

(11) Katsuki, T. Some Recent Advances in Metallosalen Chemistry. Synlett, 2003, 3, 281-297.

(12) (a) Zhang, W.; Loebach, J. L.; Wilson, S. R.; Jacobsen, E. N. Enantioselective Epoxidation of Unfunctionalized Olefins Catalyzed by Salen Manganese Complexes. J. Am. Chem. Soc. 1990, 112, 2801. (b) Irie, R.; Noda, K.; Ito, Y.; Matsumoto, N.; Katsuki, T. Catalytic Asymmetric Epoxidation of Unfunctionalized Olefins Using Chiral (Salen)manganese(III) Complexes". Tetrahedron 1991, 2, 481-494. (c) Hamada, T.; Irie, R.; Mihara, J.; Hamachi, K.; Katsuki, T. Highly Enantioselective Benzylic Hydroxylation with Concave Type of (Salen)manganese(III) Complex. Tetrahedron 1998, 54, 10017-10028.

(13) Du Bois, J.; Hong, J.; Carreira, E. M.; Day, M. W. Nitrogen Transfer from a Nitridomanganese(V) Complex: Amination of Silyl Enol Ethers. J. Am. Chem. Soc. 1996, 118, 915-916.

(14) (a) Clarke, R. M.; Storr, T. Tuning Electronic Structure to Control Manganese Nitride Activation. J. Am. Chem. Soc. 2016, 138, 15299-15302. (b) Keener, M.: Peterson, M.: Sanchez, R. H.: Oswald, V. F.: Wu, G.: Menard, G. Towards Catalytic Ammonia Oxidation to Dinitrogen: A Synthetic Cycle by Using a Simple Manganese Complex. Chem. Eur. J. 2017, 23, 11479-11484.

(15) Lindley, B. M.; Appel, A. M.; Krogh-Jespersen, K.; Mayer, J. M.; Miller, A. J. Evaluating the Thermodynamics of Electrocatalytic $\mathrm{N}_{2}$ Reduction in Acetonitrile. ACS Energy Lett. 2016, 1, 698-704.

(16) Wang, J.; Wang, H.; Guo, S.; Jia, X.; Zhong, Y.; Han, Y.; Lin, M.; Wang, S.; Zhao, F.; Fu, J.; Zhao, J. The pH Changes at the Electrode Surface Caused the New Voltammetric Waves in PCET Reactions. J. Electrochem. Soc. 2014, 161, H443-H446.

(17) Morris, W. D.; Mayer, J. M. Separating Proton and Electron Transfer Effects in Three-Component Concerted Proton-Coupled Electron Transfer Reactions. J. Am. Chem. Soc. 2017, 139, 1031210319. 


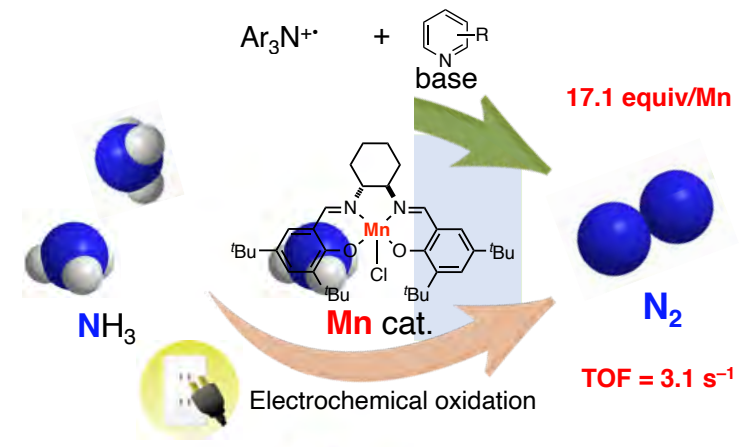

